\title{
Snap-Courses: An Instructional Design Strategy for Aviation Mobile Learning
}

\author{
Suzanne K. Kearns \\ The University of Western Ontario
}

\begin{abstract}
The aviation industry is rapidly adopting mobile technology through the use of electronic flight bags (EFBs) in cockpits. In addition to EFB charts and manuals, mobile devices can deliver instructional content to facilitate mobile learning (m-learning). However, mlearning is still in its infancy, and little work has been done to explore how people learn through this technology. This article explores how the features of mobile devices may facilitate new aviation instructional approaches, as well as a blended learning instructional design model that incorporates snap-courses. Snap-courses are short, 5minute segments of training that are designed to be distributed over several weeks or months. Snap-courses may be well suited to a mobile learning context and facilitate long-term retention.
\end{abstract}

\section{Introduction}

The aviation industry has been an early adopter of mobile technology through the use of tablet computers as electronic flight bags (EFBs; Federal Aviation Administration, 2007). The current usage of mobile technology within aviation can be classified as justin-time training or performance support. This means that information such as a textbook, chart, or checklist is stored on the mobile device and available when the operator hits a stumbling block and needs additional information.

However, the opportunities for mobile learning (m-learning) within aviation are farreaching. As these devices are increasingly used, both professionally and personally, an educational opportunity has emerged that was not previously possible. The opportunity lies in the continual access to individuals throughout their day-to-day lives. When mobile users are seeking a few minutes of entertainment, while waiting in line or sitting in a coffee shop, it is common for them to pull out their device. This continual access to learners makes it possible to take advantage of these small windows of opportunity to provide aviation training courses of a very short duration. This style of instruction may be used to enhance pilot safety skills, reinforce technical knowledge of air law, weather, and general airmanship, or to distribute information on company-specific standard operating procedures.

Within the current discussion, the term snap-course is introduced to describe a short unit of training that is about 5 minutes in length. The goal of snap-courses, taken just once or twice a week throughout the year, is to promote high levels of retention compared to levels achieved in a once-a-year visit to a classroom (Cepeda, Pashler, Vul, Wixted, \& Rohrer, 2006). The following discussion will explore the current definition of $\mathrm{m}$ learning, as well as the features of the technology, and the instructional design considerations that highlight the potential benefits of snap-courses. 


\section{What Is M-Learning?}

Generally, most people associate m-learning with the newest forms of technology, such as smartphones or tablet computers. M-learning is also commonly regarded as having evolved from personal computer-based electronic learning (e-learning). However, m-learning can exist even without such technology. For example, a person travelling with a book is participating in mobile learning (Low \& O'Connell, 2006). Ultimately, the mobile element of learning is based upon the mobility of the individual rather than the technology (Sharples, Taylor, \& Vavoula, 2005).

M-learning has been defined as "any educational provision where the sole or dominant technologies are handheld or palmtop devices" (Traxler, 2005, p. 262). However, there is some ambiguity within this definition, as one may ask if training on ultra-light laptop computers would be categorized as m-learning. The term tethered is often used to distinguish between personal computers (PCs) and mobile devices, with laptops and PCs considered to be tethered. The terms lightweight, personal, informal, spontaneous, portable, situated, and context-aware have been used to describe m-learning, whereas the terms media-rich, connected, multimedia, institutional, structured, massive, and interactive have been used to describe e-learning (Traxler, 2005).

Some of the emerging characteristics of mobile learning include personalized instruction that is spontaneous, portable, and situated. Mobile learning has also been characterized as a personal learning environment, meaning that training is learner-centric, unlike most classroom environments, which are instructor-centric (Ally, 2009).

\section{M-Learning Features}

Although m-learning is not dependent upon technology, the features of modern mobile devices allow instructors to revolutionize teaching practices. At present, these features include push notifications, location-specific applications through global positioning systems (GPS), massive storage at a low weight, and video and still camera functions.

Push notifications allow for information to be immediately sent to mobile devices, which trigger an audio alert to the user upon arrival. Aviation training applications using push notifications could include a company sending safety- or time-critical information to employees. Push notifications can be enhanced with interactivity, such as a short quiz. Companies can track which employees have looked at and responded to the push

notification, thereby eliminating the need to gather employees in a classroom to deliver short training courses.

Most modern mobile devices include GPS functionality. This allows for the development of applications that sense the location of the user and transmit critical information that is specific to that environment. Within aviation, this functionality could allow for a pilot to access weather information or navigational charts that are relevant to the pilot's current location. 
The large storage capacity and low weight of mobile devices facilitates just-in-time learning, by allowing professionals to easily carry a massive amount of information that can be used to support their performance on the job. For example, if an aviation mechanic encountered a flaw that he or she had not seen before, a mobile device that contained electronic versions of manuals would allow the mechanic to search out the information needed without leaving the aircraft. This immediate application of new knowledge facilitates high-level learning (Ally, 2009).

Finally, the video and still camera functions within mobile devices can also be used to enhance learning and performance. These devices allow users to establish a more humanistic face-to-face connection with another person, perhaps a mentor who is located in a separate geographic area. These functions also facilitate easy sharing of visual information, such as an image of a mechanical component or weather system. This can allow individuals who are deployed on-the-line to access expertise and resources at a home base.

All of these features have significant potential to transform aviation training. However, it is crucial to remember that in order for m-learning to be effective, it needs to be based on instructional design theories.

\section{M-Learning Instructional Design}

It has long been known that technology has the potential to be a powerful educational tool (Kay \& Goldberg, 1977). As we enter the era of m-learning, it is beneficial to consider the challenges faced in the early days of e-learning. Initially, many companies were eager to reap the financial benefits of e-learning, such as reducing a pilot's time offthe-line and maintaining a fully staffed training center. This eagerness resulted in a large number of e-learning courses being developed very quickly, without due consideration given to how people learn electronically.

Research into the effectiveness of e-learning found that some courses significantly outperform classroom instruction, while others do not (Bernard et al., 2004; Cavanaugh, 2001). It is assumed that e-learning courses that underperform classroom instruction were developed rapidly, without being properly tested, as this type of training became popular before anyone truly understood how to use it (Zemsky \& Massy, 2004). In addition, as a result of exposure to poorly designed e-learning, many aviation professionals developed a negative opinion of e-learning as a whole (Kearns, 2010). To avoid repeating the same mistakes made with the rapid adoption of e-learning, it is crucial that aviation training professionals carefully consider how people will learn through mobile devices, which represent an entirely new medium.

Ultimately, the effectiveness of the training is more important than the nature of the technology. Unfortunately, instructional design theories for mobile platforms are immature compared to e-learning or classroom-based training (Gedik, HanciKarademirci, Kursun, \& Cagiltay, 2012). Some theories developed for e-learning can be adapted and applied to m-learning, yet there are many more questions than answers about how people learn through mobile devices. 
For example, a significant body of research has explored how learning is impacted by the environment within which instruction is delivered. Contextual learning theory suggests that the more realistic the instructional environment, the more likely it is that learners will be able to apply new knowledge in the real world (Jonassen, 1993). Contextual learning theory is the foundation of problem-based learning (PBL), and is the reason why many instructors present real-world examples so that learners can relate new knowledge to their own experiences (Hull, 1993). Another interesting example of context impacting learning is that seating comfort impacts one's performance and ability to pay attention (Gay, 1986; Tessmer \& Harris, 1992). Yet, with mobile learning, such a consideration is inherently unpredictable. Learners may complete m-learning while walking, sitting in a coffee shop, or travelling on a bus or aircraft. It is important to anticipate that a mobile context will create a new relationship with training, compared to traditional e-learning or classroom instruction.

Within the instructional design process, careful consideration must be given to exploring the characteristics of learners. With m-learning, acceptance of technology is likely to vary between generations. Prensky (2001) originated the terms digital immigrants and digital natives. The concept is that those who did not have access to digital technology in their youth must take on the challenge of learning to use digital technology in their adulthood; thus they are digital immigrants. By comparison, younger generations are digital natives, as digital technology has always been a part of their lives. Similarly, it can be expected that there will be a divide between mobile immigrants and mobile natives (Low \& O'Connell, 2006). This generation-gap theory is supported by the prevalence of mobile technology among teenagers (Gedik et al., 2012).

However, there will always be a segment of the population who do not own, or cannot afford to maintain access to, mobile technology. In addition, there is a lack of compatibility between types of mobile devices (currently the main three being Apple, Blackberry, and Android). This makes m-learning design difficult, increases development costs, and makes it challenging to reach all mobile users.

Yet, m-learning may have a large impact on developing nations. In many countries with limited access to PCs, the number of mobile phones is relatively high. In fact, it has been suggested that it would be a serious disservice to teachers and learners in Asian and African countries if these countries were to move toward e-learning instead of m-learning (Motlik, 2008). It is logical for these nations to move directly to mobile learning, based on the ease of use, prevalence of mobile technology, and students' and instructors' familiarity with the technology.

\section{Blended Learning Approach}

Blended learning is a term used to describe a program that incorporates two or more types of instruction. Pilot training is a natural example of blended learning, as it combines elements of classroom instruction with training in an aircraft or flight simulator. For job-relevant knowledge and skills, blended learning that includes both elearning and classroom instruction has been found to be more effective than either 
approach alone (Sitzmann, Kraiger, Stewart, \& Wisher, 2006; Zhao, Lei, Yan, Lai, \& Tan, 2005).

To determine which delivery methods to choose within a blended learning approach, a four-part process is recommended (Kearns, 2010):

1. Consider the cognitive, psychomotor, and affective training objectives.

2. For each of the objectives, consider the following:

a. What is the best teaching activity to accomplish this objective?

b. Is human interaction required?

c. How could this instruction be delivered?

3. Then, list which activities should be accomplished before classroom training, which activities require human interaction or specialized equipment (like a flight simulator), and which activities can be delivered on-the-line once learners have returned to their job. These three components make up the aviation blended learning model:

a. Pre-learning (e-learning, m-learning)

b. Training center (classroom and/or simulator)

c. On-the-line (e-learning, m-learning) (pp. 111-113).

Organizational factors, such as a company's training budget or a culture of being early adopters of technology, often impact instructional delivery decisions. However, it is crucial to remember that the ultimate goal of training is not to implement a new technology, but to accomplish training objectives. Training should be designed to maximize learning with the minimum cost.

Horton (2006) suggested a "sandwich" strategy for blended learning, placing classroom instruction after and before e-learning or m-learning elements. This strategy has been adapted for aviation companies to create the pre-learning, training center, onthe-line blended learning model shown in Figure 1 (Kearns, 2010). Pre-learning is accomplished through e-learning or m-learning. Pre-learning is meant to deliver the foundational knowledge and skills that learners require before classroom and simulator instruction. Training center learning is classroom and simulator-based instruction, specifically for topics that require human interaction, aircraft, or specialized equipment (such as flight simulators). On-the-line training extends training beyond the classroom to the workplace, and is accomplished through e-learning or m-learning. 


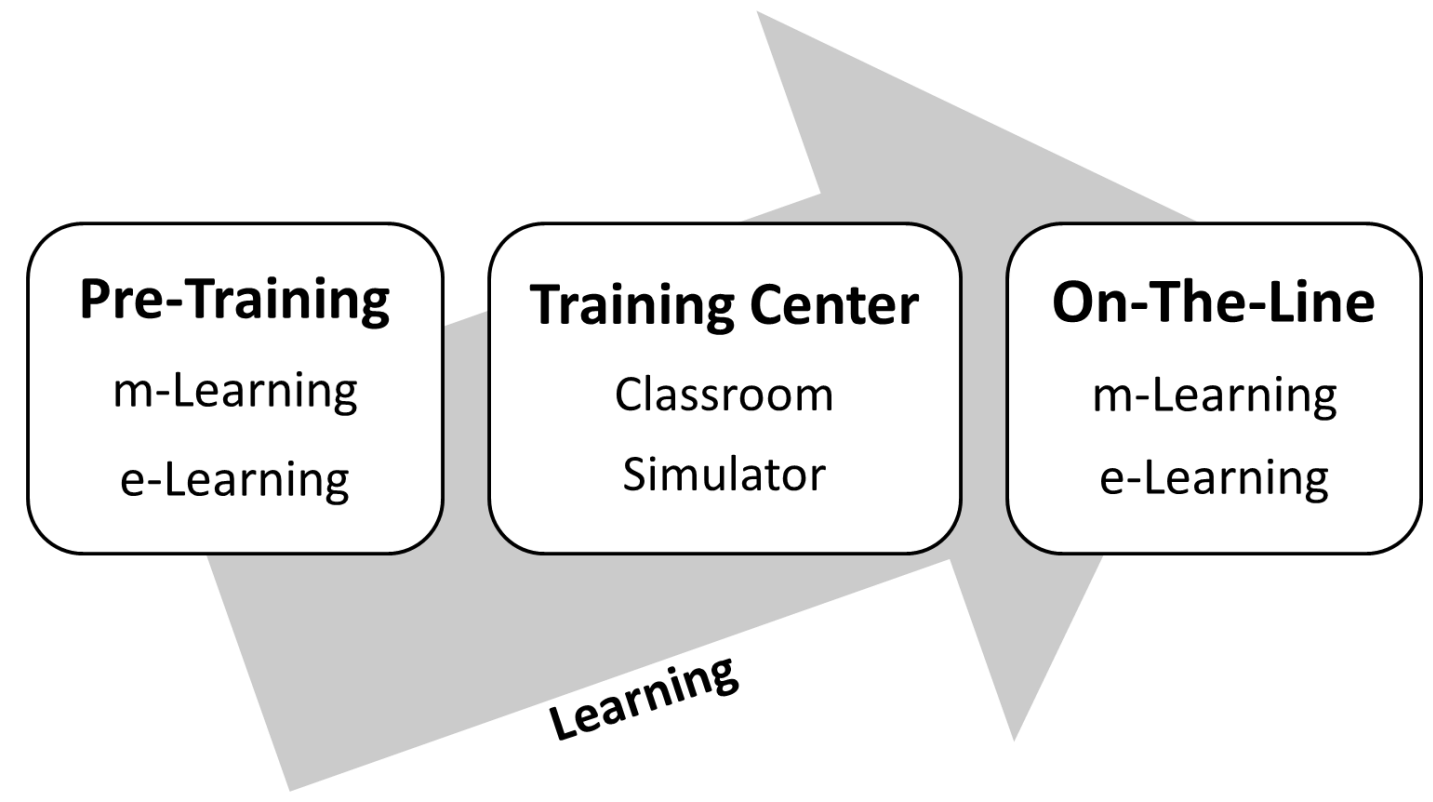

Figure 1. Kearns's (2010) aviation blended learning model.

An advantage of on-the-line training is that distributed practice has been shown to reduce the forgetting that occurs naturally after classroom instruction (Ebbinghaus, 1964). Distributed practice refers to a series of short courses spread out over time, compared to massed practice, which refers to a longer single session of training. When comparing the effectiveness of massed to distributed practice, researchers equate the duration of a single session of massed training to the cumulative duration of a series of short distributed practice sessions (Cepeda et al., 2006). For example, one hour of massed practice within a classroom could be compared against a series of twelve 5minute distributed practice courses spread out over several weeks. Several major quantitative and qualitative reviews have determined that distributed practice results in increased retention over massed practice (Cepeda et al., 2006; Donovan \& Radosevich, 1999; Greene, 1992; Janiszewski, Noel, \& Sawyer, 2003; Lee \& Genovese, 1988).

Of course, a major challenge in designing on-the-line distributed practice within aviation is that it is expensive and logistically challenging to bring professionals back to a classroom on a continual basis. However, m-learning technology facilitates this type of distributed practice.

\section{Snap-Courses}

A snap-course is only about 5 minutes long and is an increment of a larger m-learning module. Snap-courses are meant to facilitate distributed practice, and therefore are designed to be completed over a longer period of time rather than in a single session. Snap-courses represent an instructional design strategy that is unique to m-learning. It is expected that the short duration will suit mobile contexts in which it may be unrealistic for a learner to remain focused for a continued amount of time within a variable environment filled with distractions. 
The recommended characteristics of snap-courses include the following:

- Approximately 5 minutes in duration

- Include interactivity

- Design for personalization, rewards, and choice to facilitate intrinsic motivation (Cordova \& Lepper, 1996; Dickinson, 1995)

- Facilitate discussions among learners

- Incorporate repetition to promote retention

- Integrate quizzes that facilitate retrieval practice (Roediger \& Butler, 2011)

- Allow learners to choose a convenient time to complete training

- Encourage learners to complete training over a longer period of time.

M-learning allows for the aviation industry to create a continual training cycle at a reasonable cost, delivering snap-courses throughout the year to facilitate high levels of retention. This continual access to learners is something that was not possible before the proliferation of mobile devices.

The aviation blended learning model, while incorporating snap-courses, recognizes that not all training is feasible through technology. Classroom instruction can be valuable when it is used effectively to build upon existing knowledge. It is possible to enhance student learning through a training design that incorporates classroom instruction and technology-based learning. This model pieces apart the aspects of training that do not require human interaction and therefore can, and should, be delivered through technology to maximize efficiency while minimizing costs (Kearns, 2010).

\section{Conclusion}

The aviation industry is rapidly adopting mobile technology and EFBs. However, it is important for the industry to exercise caution and to remember that it is the learning that matters, rather than the technology. In order to avoid the rapid but poor-quality development that occurred with early e-learning, aviation training professionals need to recognize that sound instructional design is more important than the technology being used. E-learning instructional design principles can be adapted for mobile platforms; however, m-learning is still in its infancy. Systematic investigation is required to determine the characteristics of m-learning that maximize training effectiveness and to measure the impact of snap-courses on retention. In addition, continual research must be conducted not only to assess how people learn through mobile technology and how snapcourses affect retention, but also to identify variations between e-learning and m-learning practices. However, if introduced thoughtfully, it is possible that mobile technology may extend instructional capability beyond what was possible in a classroom and revolutionize an individual's relationship with training. 


\section{References}

Ally, M. (2009). Mobile learning: Transforming the delivery of education and training. Edmonton, AB: AU Press.

Bernard, R. M., Abrami, P. C., Lou, Y., Borokhovski, E., Wade, A., Wozney, L., . . Huang, B. (2004). How does distance education compare with classroom instruction? A meta-analysis of the empirical literature. Review of Educational Research, 74, 379-439.

Cavanaugh, C. S. (2001). The effectiveness of interactive distance education technologies in K-12 learning: A meta-analysis. International Journal of Educational Telecommunications, 7, 73-88.

Cepeda, N. J., Pashler, H., Vul, E., Wixted, J. T., \& Rohrer, D. (2006). Distributed practice in verbal recall tasks: A review and quantitative synthesis. Psychological Bulletin, 132, 354-380.

Cordova, D. I., \& Lepper, M. R. (1996). Intrinsic motivation and the process of learning: Beneficial effects of contextualization, personalization, and choice. Journal of Educational Psychology, 88, 715-730.

Dickinson, L. (1995). Autonomy and motivation a literature review. System, 23, 165-174.

Donovan, J. J., \& Radosevich, D. J. (1999). A meta-analytic review of the distribution of practice effect. Journal of Applied Psychology, 84, 795-805.

Ebbinghaus, H. (1964). Memory: A contribution to experimental psychology (H. A. Ruger, C. E. Bussenius, \& E. R. Hilgard, Trans.). New York, NY: Dover.

Federal Aviation Administration. (2007). Use of Class 1 or Class 2 Electronic Flight Bag (EFB). Retrieved from http://rgl.faa.gov/Regulatory_and_Guidance_Library /rgAdvisoryCircular.nsf/list/AC\%2091-78/\$FILE/AC\%2091_78.pdf

Gay, K. (1986). Ergonomics. Hillsdale, NJ: Enslow.

Gedik, N., Hanci-Karademirci, A., Kursun, E., \& Cagiltay, K. (2012). Key instructional design issues in a cellular phone-based mobile learning project. Computers \& Education, 1149-1159.

Greene, R. L. (1992). Human memory: Paradigms and paradoxes. Hillsdale, NJ: Erlbaum.

Horton, W. (2006). E-learning by design. San Francisco, CA: Pfeiffer.

Hull, D. (1993). Opening minds, opening doors: The rebirth of American education. Waco, TX: Centre for Occupational Research and Development. 
Janiszewski, C., Noel, H., \& Sawyer, A. G. (2003). A meta-analysis of the spacing effect in verbal learning: Implications for research on advertising repetition and consumer memory. Journal of Consumer Research, 30, 138-149.

Jonassen, D. (1993). The trouble with learning environments. Educational Technology, 33(1), 35-37.

Kay, A., \& Goldberg, A. (1977). Personal dynamic media. IEEE Computer, 10(3), 31-41.

Kearns, S. K. (2010). E-learning in aviation. Burlington, VT: Ashgate.

Lee, T. D., \& Genovese, E. D. (1988). Distribution of practice in motor skill acquisition: Learning and performance effects reconsidered. Research Quarterly for Exercise and Sport, 59, 277-287.

Low, L., \& O’Connell, M. (2006). Learner-centric design of digital mobile learning. Retrieved from http://citeseerx.ist.psu.edu/viewdoc/download?doi=10.1.1.123.48\&rep=rep1\&typ $\mathrm{e}=\mathrm{pdf}$

Motlik, S. (2008). Mobile learning in developing nations. International Review of Research in Open and Distance Learning, 9(2). Retrieved from http://www.irrodl.org/index.php/irrodl/article/viewArticle/564/1039

Prensky, M. (2001). Digital natives, digital immigrants. On the Horizon, 9(5), 1-6.

Reigeluth, C. M. (1999). Instructional design theories and models: A new paradigm of instructional theory (Vol. II). Mahwah, NJ: Erlbaum.

Roediger, H. L., III, \& Butler, A. C. (2011). The critical role of retrieval practice in longterm retention. Trends in Cognitive Sciences, 15(9), 20-27.

Sharples, M., Taylor, J., \& Vavoula, G. (2005). Towards a theory of mobile learning. Retrieved from http://www.mlearn.org.za/CD/papers/Sharples\%20Theory\%20of\%20Mobile.pdf

Sitzmann, T., Kraiger, K., Stewart, D., \& Wisher, R. (2006). The comparative effectiveness of web-based and classroom instruction: A meta-analysis. Personnel Psychology, 59, 623-664.

Tessmer, M., \& Harris, D. (1992). Analysing the instructional setting: Environmental analysis. London, England: Kogan Page.

Traxler, J. (2005). Defining mobile learning. In Proceedings of the IADIS International Conference: Mobile Learning 2005 (pp. 261-266). Qawra, Malta: IADIS. 
Zemsky, R., \& Massy, W. F. (2004). Thwarted innovation: What happened to e-learning and why. Retrieved from http://www.cedmaeurope.org/newsletter\%20articles/misc/ThwartedInnovation\%20(Jun\%2004).pdf

Zhao, Y., Lei, J., Yan, B., Lai, C., \& Tan, H. S. (2005). What makes the difference? A practical analysis of research on the effectiveness of distance education. Teachers College Record, 107, 1836-1884. 